\title{
Biomineralization of (Fe,Mn)-rich silicates in an oxic environment by oxygenic photosynthesizers
}

\author{
KARIM BENZERARA ${ }^{1}$, MARIA CIOBANU ${ }^{2}$, AGNÈS \\ ELMALEH $^{1}$, MIGUEL INIESTO ${ }^{2}$, DIDIER JÉZÉQUEL ${ }^{3}$, \\ PURIFICACIÓN LÓPEZ-GARCÍA ${ }^{2}$, NICOLAS MENGUY ${ }^{1}$, \\ FÉRIEL SKOURI-PANET ${ }^{1}$, ROSALUZ TAVERA ${ }^{4}$ AND \\ DAVID MOREIRA ${ }^{5}$
}

${ }^{1}$ IMPMC, CNRS, Sorbonne Université, MNHN

${ }^{2}$ Unité d'Ecologie Systématique et Evolution, CNRS, Université Paris-Saclay, AgroParisTech

${ }^{3}$ Université de Paris-Institut de Physique du Globe de ParisCNRS, UMR 7154

${ }^{4}$ Departamento de Ecología y Recursos Naturales, Universidad Nacional Autónoma de México

${ }^{5}$ Unité d'Ecologie, Systématique et Evolution, CNRS UMR 8079, Université Paris Sud

Presenting Author: karim.benzerara@upmc.fr

The emergence of oxygenic photosynthesis has dramatically modified the geochemical functioning of the Earth's surface. After some time, it has resulted in the oxygenation of the ocean and the atmosphere, significantly modifying chemical equilibria and the speciation and availability of numerous dissolved species, especially metals. As a consequence, the chemical compositions of authigenic phases forming in surface environments have changed to $\mathrm{Fe}$ and $\mathrm{Mn}$-poor endmembers. This "rule" has fed the use of the metal (e.g., Fe, Mn) content of mineral phases as a proxy to track oxygenation in the geological record, especially during this transition from an anoxic to an oxic Earth's surface.

Here we report a new biologically-mediated process which seems to violate this rule. Indeed, we discovered cyanobacteria able to form under apparent disequilibrium, Fe- and Mn-rich authigenic silicate phases in an oxic and alkaline environment. These cyanobacteria have been detected at relatively high abundance and at all depths in the water column of a volcanic crater lake in the Puebla state, Mexico. Using a variety of spectroscopy and microscopy tools down to the nm-scale, we described how the biomineralized silicates are arranged with respect to the cells and their polymers, and determine their chemical composition and cristallinity. Moreover, we obtained the 16S rRNA gene sequence and identified these cyanobacteria as members of the order Synechococcales. Last, we found that the authigenic (Fe,Mn)-rich bio-silicates are preserved upon their settling in the water column and sedimentation at the bottom of the lake. In conclusion, we will speculate about involved mechanisms and the possible biological distribution of such a process. 